\title{
Ore prospects of Heibei Quzhou based on aeromagnetic anomalies
}

\author{
Qiankun Liu' ${ }^{1}$, Rong Yang ${ }^{2}$ \\ ${ }^{1}$ China Aero Geophysical Survey and Remote Sensing Center for Land and Resources, Beijing \\ 100083, China \\ ${ }^{2}$ Sichuan Geological Survey, Chengdu 610081, China
}

Keywords: Quzhou, aeromagnetic, the mineral prospects.

\begin{abstract}
Hebei Quzhou aeromagnetic anomalies is located in near Handan Iron ore concentration area, Through the anomaly area geological structure characteristics, rock ore property and magnetic anomaly characteristics of comprehensive study, that it has the potential to Quzhou aeromagnetic anomalies further search of iron ore. And then using 2.5D fitting technique quantitatively fitting calculation, think Quzhou aeromagnetic anomalies have some prospecting potential, but its iron ore layer buried deeper.
\end{abstract}

\section{Introduction}

Quzhou abnormal area is located in Handan, Hebei Province; the southern end of the abnormal area is about $40 \mathrm{~km}$ away from Handan City, Quzhou area in the 1960s carried over 200000 aeromagnetic measurements, parts of the Northeast in the 1970s carried out over a: 50000 aeromagnetic measurements. In the 1980s and 2008, in Hebei province had been carried out a comprehensive study aeromagnetic anomalies of Quzhou been discussed, believed to have mineral prospects (Xiangqun Qian, 1986).

\section{Geological background}

Quzhou area is located to the east of the fault zone in southeastern North Taihang Mountains, North China Craton Taihang station Muan concave arch beam of West Duanzhe, Shanxi uplift above, belonging to the new Chinese structural system.

Quzhou abnormal area is all quaternary cover (Figure 1). Han Xing western region is exposed areas, mainly exposed Archean metamorphic rocks, the Great Wall of discipline and Cambrian Ordovician carbonate rocks and Carboniferous - Permian coal-bearing strata, etc.; magmatic rocks exposed much, just a Jurassic diabase, diorite and Cretaceous syenite and other small rock distribution.

From the Han Xing geological map and previous research results to know: Han xing area ancient basement in archean ZanHuang group, and relationship with the overlying formation in angular unconformity, lithology is mainly gneiss and some schist, amphibolite rock, marble and so on. Cover layer from bottom to top is the Great Wall of discipline capping marine clastic rocks of the Cambrian - Austrian Taoji Bin shallow marine carbonate rocks and Carboniferous - Permian paralic coal-bearing rocks. Middle Ordovician Majiagou and peak group is a set of marine carbonate rocks, mainly limestone and marble class, the lower growth in each group were associated breccia layer of gypsum and other salts, is in the area of iron deposits main ore-controlling strata.

Han Xing region have Wuan Xishimen iron ore a large, there are 22 such as the Zhong Guan, Yu Shi Tang, Yang Er Zhuang and other medium-sized and small iron ore multiple. Iron ore type, the four areas in the west (Tong Yu, Shanxi) is a sedimentary-metamorphic (Guoqiang Li, 2008). Skarn iron mainly in Jurassic diorite and outside the contact zone Majiagou Ordovician carbonate rocks and peak group, the sedimentary-metamorphic iron ore is mainly produced in the Archean metamorphic rocks. 


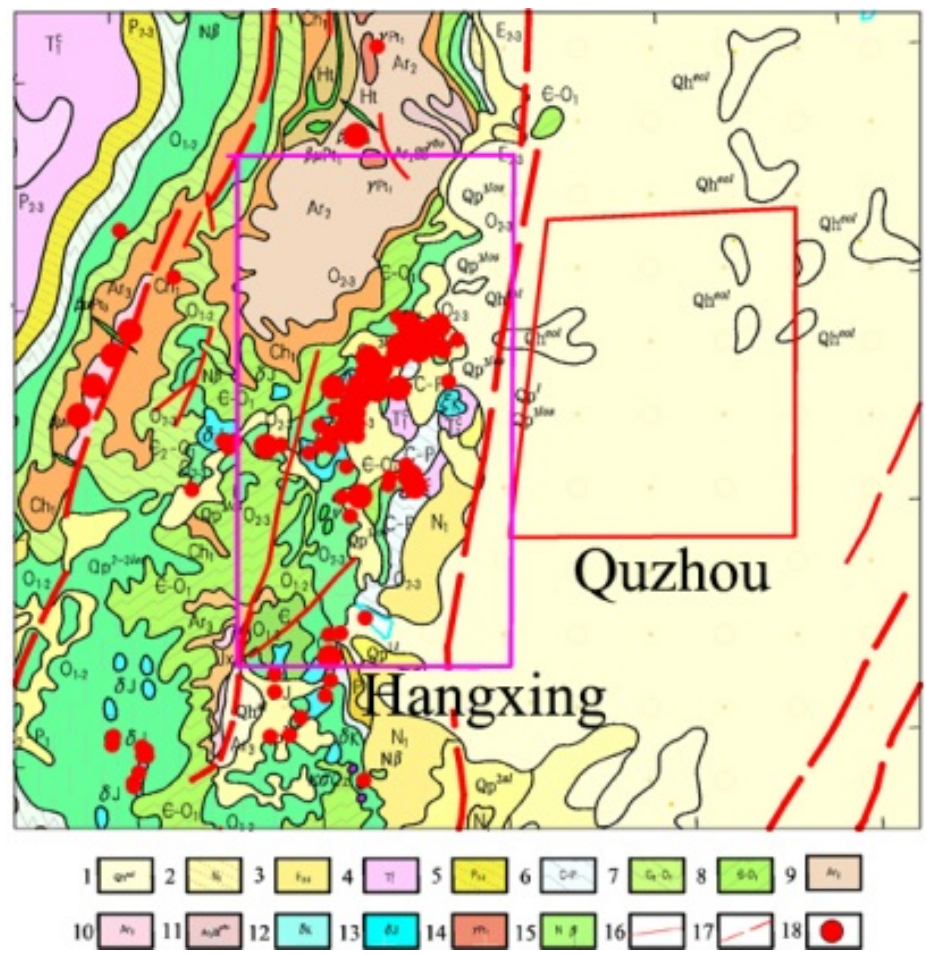

1- Quaternary; 2 - mudstone, shale; 3- conglomerate, siltstone; 4- sandstone; 5- clastic; 6- carbonate rocks; 7- quartz sandstone; 8- dolomite; 9- hornblende plagioclase gneiss, amphibolite rocks; 10 amphibolite rock, magnetite quartzite; 11- tonalite gneiss; 12- Cretaceous granites; 13- Jurassic flash long rocks; 14- COSCO ancient granite; 15- olivine basalt; 16- found fault; 17- buried fault; 18known iron ore

\section{Rock (ore) physical characteristics}

The magnetic data of rocks and minerals statistical results show that Magnetic sedimentary rocks are generally not strong, were less than $160 \times 10$-6SI; pre-Sinian metamorphic rocks generally have magnetic, but all kinds of metamorphic rocks of different magnetic variation range is $160 \sim 5040 \times$ $10^{-6} \mathrm{SI}$, which dioritic gneiss is $2043 \sim 5040 \times 10^{-6 S I}$, granitic gneiss is $80 \sim 3232 \times 10^{-6} \mathrm{SI}$, sedimentary rocks (such as phyllite, mica schist, etc.) is generally less than $160 \times 10^{-6} \mathrm{SI}$; Susceptibility and residual magnetization Jurassic diorite were $4775 \sim 5944 \times 10^{-6} \mathrm{SI}, 770 \times 10^{-3} \mathrm{~A} / \mathrm{m}$ or so; susceptibility and residual magnetization of iron ore were $200000 \times 10^{-6} \mathrm{SI}, 53000 \times 10^{-3} \mathrm{~A} / \mathrm{m}$ or so. Tianjin Geological Survey center drill core measurements show that the Quaternary magnetic susceptibility is generally a few to several tens $\times 10^{-6} \mathrm{SI}$, basaltic tuff susceptibility is generally $200 \sim$ $600 \times 10^{-6} \mathrm{SI}$, basalt magnetic susceptibility is generally $5500 \sim 7000 \times 10^{-6} \mathrm{SI}$.

\section{Regional aeromagnetic anomalies}

According to 1: 2500000 aeromagnetic map (Figure 2), Han Xing - Quzhou area is a large positive anomaly zone, by CI, CII and CIII3 a partial positive anomaly components. CI abnormalities in Xingtai - Li City area is divided into north and south two to 200nT equivalent secondary coil set abnormalities, west huangcun abnormal of northern section 200nT circle corresponded with Archean metamorphic, metro contour within the southern end of 200nT - Muan anomaly with multiple abnormalities centers and Han Xing ore zone corresponds better, north-South boundary is unusual in this area north margin magmatic activity. CII abnormal morphology, size is in accordance with the concept of dragon uplift. CIII exception was extended north east, with unusual characteristics CII No similar inference is caused by basement uplift. Caiqin Zeng (1987) by the geological structure of the region aeromagnetic studies, think Han Xing regional and zonal structure exists basement of Quzhou area, to provide a channel of magma intrusion and deposits was controlled by structure. 


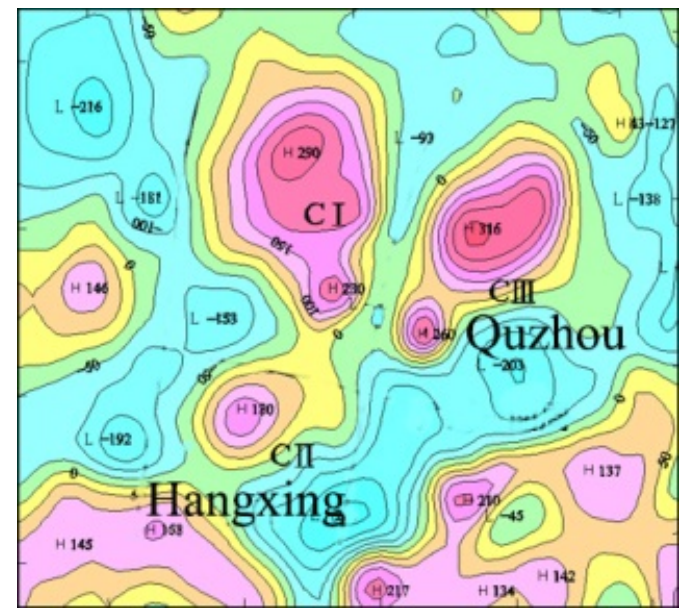

Figure 2 Han Xing - Quzhou regional aeromagnetic anomaly map

\section{Local aeromagnetic anomalies}

According to 1: 50000 aeromagnetic series (Figure 3a b), Quzhou aeromagnetic anomalies mainly by the Qu A and Qu B consisting of two local anomalies.

Qu A abnormal is located in the southwest of Quzhou unusual, belongs to calm rising local magnetic anomalies in the area, nearly oval shape, the long axis nearly north-east towards the larger strength, up 504nT, steep gradient, unusual clear boundary. Qu B abnormal is located in the middle of Quzhou abnormal, belongs to a quiet area of elevated magnetic local anomaly, nearly oval shape, the long axis nearly north-east towards the main anomaly intensity is generally $100 \sim 250 \mathrm{nT}$, up 257nT.

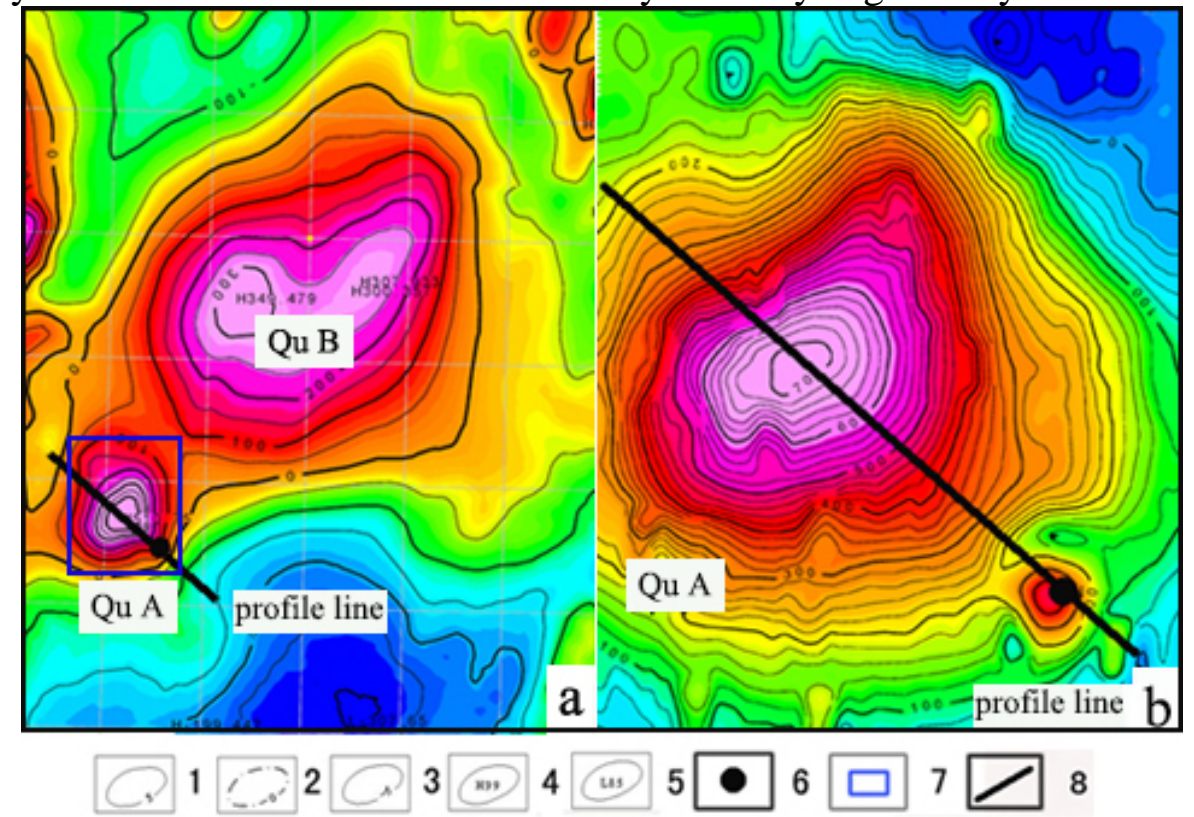

Figure 3 Quzhou regional aeromagnetic - magnetic anomaly map a- aeromagnetic $\triangle \mathrm{T}$ of extreme contour plan; b- Geomagnetic contour plan;

1- Magnetic contours and are marked; 2 - zero magnetic contours and labeling; 3- magnetic negative contours and labeling; 4- Relatively high magnetic and annotation; 5- relatively low magnetic and annotation; 6- drilling position; 7- geomagnetic prospecting range; 8- quantitative calculation profile position

The anomalous area is completely covered by Quaternary. Tianjin all center on the protruding nose in southeast anomaly drilling verification, meet tertiary basalt class between $256 \sim 582 \mathrm{~m}, 1170$ $\mathrm{m}$ when end hole is still the tertiary. In the drill as a constraint, through A unusual piece of north west section $2.5 \mathrm{D}$ fitting calculation, the results are shown in figure $4 \mathrm{~A}$ and $\mathrm{b}$. Figure 4 and figure $4 \mathrm{~b}$ the difference between different geological model, the former hypothesis underground ore body, the magnetic model body mainly use the tertiary basalt $(\mathrm{J}=3 \mathrm{a} / \mathrm{m}$, buried depth of about $250 \mathrm{~m})$; the latter 
hypothesis is underground ore body, magnetic model body mainly use the tertiary basalt $(\mathrm{J}=3 \mathrm{a} / \mathrm{m}$, buried depth of about $250 \mathrm{~m}$ ), intermediate-acid intrusive rocks $(\mathrm{J}=2 \mathrm{a} / \mathrm{m}$, buried depth of about 2000 $\mathrm{m})$ and concluded that the iron ore body $(\mathrm{J}=80 \mathrm{a} / \mathrm{m}$, buried depth of about $2000 \mathrm{~m})$. Because not been found in North China over 2000m thick Tertiary basalt, it is considered the model shown in Figure 4b is more reasonable to infer that it is unusual mainly caused by magnetite buried deeper.
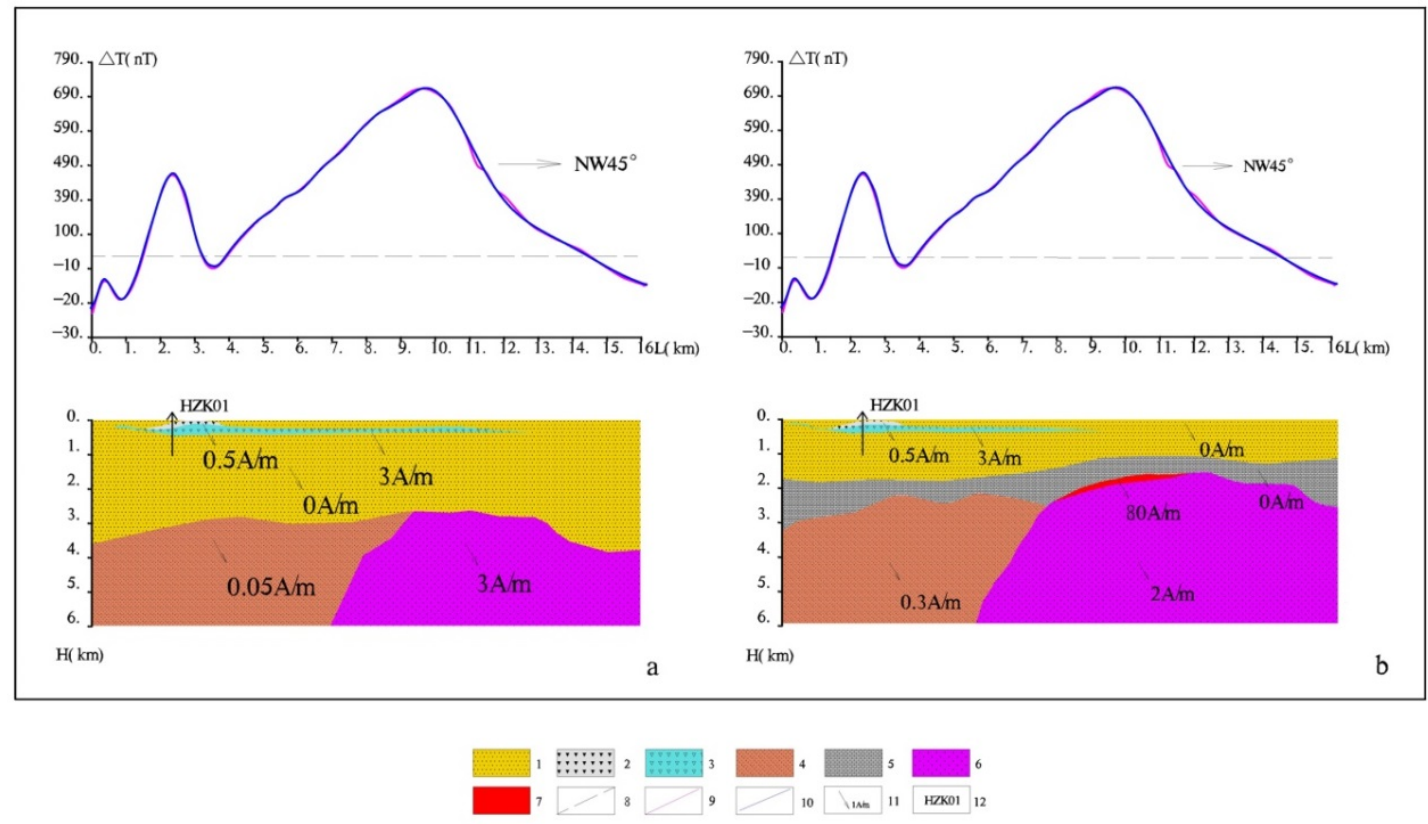

Figure 4 Quzhou geomagnetic anomaly sectional view of the forward fitting calculation 1- Quaternary and Tertiary; 2 - tuff; 3- basalt; 4 - crystalline bedrock; 5- limestone; 6- diorite; 7inferred magnetite body; 8- zero line; 9- The original curve; 10- fitting curve; 11- magnetization direction and magnetization; 12- drilling and number

\section{Conclusions}

Quzhou aeromagnetic anomalies greater intensity, according to the gravity magnetic anomaly characteristics, the characteristics of geology and mineral resources and petrophysical parameters comprehensive analysis, etc., and calculate the inversion results by quantitative two geological model, infer Quzhou aeromagnetic anomalies should be mainly composed mainly insidious Tertiary basalt acidic intrusive rocks and Archean crystalline bedrock and buried deep Comprehensive cause magnetite body, inferred iron ore depth greater than $2000 \mathrm{~m}$. The inversions of aeromagnetic anomalies have multiple solutions, it is recommended for Quzhou detailed aeromagnetic anomalies verification, abnormal areas in the deep drilling verified.

\section{Acknowledgements}

Financial support for this work was provided by Key laboratory of airborne geophysics and remote sensing geology (AGRS).

\section{References}

[1] Xiangqun Qian, 1986, Han Xing regional iron ore Experience, Geology and prospecting, Vol.22 (6): 1-3.

[2]Caiqin Zeng, 1987, Han Xing unusual geological study area based on aeromagnetic, Geology and prospecting, Vol.23 (9): 39-45

[3]Guoqiang Li, 2008. Han Xingtie Cheng metallogenic rock occurrence and prospecting direction, Natural sciences. 